\title{
Stroboscopic Visual Training: a Pilot Study with Three Elite Youth Football Goalkeepers
}

\author{
Luke Wilkins $^{1}$ (D) $\cdot$ Carl Nelson $^{2} \cdot$ Simon Tweddle $^{2}$
}

Received: 21 June 2017 / Accepted: 22 August 2017 /Published online: 5 September 2017

(C) The Author(s) 2017. This article is an open access publication

\begin{abstract}
Stroboscopic visual training (SVT) is a recent tool aimed at improving visual and perceptual performance by having .individuals perform activities under conditions of intermittent vision. Research has shown it to improve skills such as visual memory (Appelbaum et al. Attention, Perception, \& Psychophysics 74 1681-1691, 2012), anticipation (Smith and Mitroff International Journal of Exercise Sciences 5 344-353, 2012), and dynamic acuity (Holliday All Graduate Plan B and Other Reports 262, 2013), whilst the anecdotal evidence for its benefits is even greater (Athletic Republic NFL Players SEE SPORT BETTER with the Nike SPARQ Vapor Strobe [video file], 2011). The present pilot study is novel in SVT research in its inclusion of qualitative data collection methods and its use of participants. Three elite, youth football goalkeepers (EG) took part in a 7-week SVT programme, and their performance on 10 measures of visual and perceptual skills was compared with three matched control participants (CG). Individual, semistructured interviews were also conducted with the EG participants prior to the post-test. In general, there were no differences in the changes from pre-test to post-test and retention test between EG and CG participants in 9 of the 10 measures. EG participants did, however, show consistent improvements in visual response time at post-test and retention test, whilst the CG participants did not. Thematic analysis of the interview data identified three themes: (1) the belief that SVT improved visual and perceptual skills, notably "reactions", "judgement", and "focus", (2) the belief that SVT improved on-field goalkeeping
\end{abstract}

Luke Wilkins

luke.wilkins@ncl.ac.uk

1 School of Biomedical Sciences, Faculty of Medical Sciences, Newcastle University, Newcastle upon Tyne NE2 4HH, UK

2 Newcastle United Football Club, Newcastle upon Tyne, UK performance, and (3) that SVT was both effortful and enjoyable. The present study provides preliminary work with implications for coaching in football goalkeeping and should be expanded with future studies that utilise larger samples and measures of motor/sporting performance.

Keywords Stroboscopic visual training $\cdot$ Vision $\cdot$ Perception

\section{Introduction}

Stroboscopic visual training (SVT) is the practice of placing individuals under conditions of intermittent vision, often using specialised eyewear, in an attempt to enhance visual and perceptual skills. From a sporting perspective, these improvements then, in theory, transfer to improved motor performance. The area has seen a substantial growth in attention since 2011 and has become a popular tool in sports vision training.

The theory underpinning SVT is that the reduction in visual samples received forces the individual to utilise the remaining samples more efficiently and makes greater use of other senses, such as kinaesthetic awareness. Skills such as central-field motion sensitivity (Appelbaum et al. 2011), short-term visual memory (Appelbaum et al. 2012), anticipation (Smith and Mitroff 2012), dynamic visual acuity (Holliday 2013), processing speed (Wilkins and Gray 2015), and accommodation (Appelbaum et al. 2016) have all been found to improve following a period of SVT. Whilst effects on motor performance are less researched, a pilot study by Mitroff et al. (2013) showed a considerable increase in ice hockey shooting and passing performance for individuals who underwent SVT, whilst a control group saw no such improvements. Other studies have incorporated SVT as one of multiple tools in a visual training programme and found significantly increased baseball batting 
metrics (Clarke et al. 2012) and significantly reduced concussion incidence (Clarke et al. 2015). Appelbaum and Erickson's (2016) review of sports vision training techniques provides more detail on some of these studies.

Despite this work, the area is still in its early stages, and there is a need for more exploratory research that includes a qualitative approach, particularly when there is considerable anecdotal evidence to support it (Athletic Republic 2011). Furthermore, it is logical to assume that the benefits of SVT may apply to our visual and perceptual skills, but knowing which tests and measures to include from such a wide-ranging area is still unclear. Much of the existing research has tended to focus on only one or two aspects such as anticipation (Smith and Mitroff 2012) or dynamic visual acuity (Holliday 2013). How SVT may affect other areas such as response inhibition is still unknown. It has also been suggested that visual training programmes should target the limiting factors in an athlete's performance (Abernethy and Wood 2001), and given that elite athletes possess considerably higher physical and technical abilities, it is reasonable to believe that the effects of SVT may be greater for such individuals compared to intermediate athletes or novices. Previous studies have included the use of such samples (e.g. Mitroff et al. 2013), but more are warranted.

\section{Aims of the Present Study}

Given the constant desire to find marginal gains in professional sport, the prospect of improving visual and perceptual skills to gain an advantage has become increasingly popular (Williams et al. 2011). SVT provides a new and promising method to achieve this, but the literature is still in its infancy and more research is needed to confirm its usefulness as a training tool for coaches and athletes. The present work is a pilot study that takes a case study approach to explore the effects of SVT on various visual and perceptual skills of three elite youth goalkeepers in football.

Based on previous research (e.g. Appelbaum et al. 2011; Appelbaum et al. 2012; Smith and Mitroff 2012; Wilkins and Gray 2015), it is hypothesised that the participants who undergo SVT will improve their performance on a battery of visual and perceptual tests, whilst the control participants will have no change in test performance. A thematic analysis of the qualitative data from one-to-one interviews with the experimental participants will also indicate the positive benefits of SVT.

\section{Methods}

\section{Participants}

Six goalkeepers from Newcastle United Football Club's academy took part in the study, with three assigned to the stroboscopic training (EG), and the other three acting as a control (CG). Participants were matched as closely as possible on age and pre-test visual and perceptual performance. The goalkeepers ranged in age from 16 to 19 years old and were all of an elite level undergoing full-time football training. The study was approved by the Faculty of Medical Sciences Research Ethics Committee, part of Newcastle University's Research Ethics Committee.

\section{Apparatus}

Participants completed the computer-based tests using a Toshiba Tecra R940-1JG laptop. This has an Intel Core i5 processor with a 256-GB SSD and an Intel HD Graphics 4000. The screen has a 14-in. non-reflective display with a $1920 \times 1080$-pixel resolution. The "Reaction Test Pro" app (version 4.0) was completed using a 16-GB Apple iPhone 6. This has a 4.7-in. LED display and a $1334 \times 750$-pixel resolution. All tests, excluding the Reaction Test Pro, were completed using a standard computer keyboard and wireless computer mouse.

Five of the tests used were taken from the Psychology Experiment Building Language (PEBL), a free computersoftware package containing around 70 behavioural tests designed for use in psychological experiments (http://pebl. sourceforge.net/). A detailed explanation of the software was published by Mueller and Piper (2014).

The stroboscopic effect used in the training programme was created by having participants wear the Senaptec Strobe glasses (http://www.senaptec.com) shown in Fig. 1. These glasses flicker from clear to opaque states at eight different frequencies, ranging from $6 \mathrm{~Hz}$ (level 1; deemed easiest due to receiving the most visual samples) to $1 \mathrm{~Hz}$ (level 8; deemed hardest due to receiving the fewest visual samples). The stroboscopic effect can also be adjusted across three modes: that of both eyes, only the left eye, and only the right eye (when in one-eye mode, the non-strobing lenses remain in the opaque state). These glasses are similar in design to the Nike SPARQ Vapor Strobe eyewear used in much of the previous research, as well as other products like the MJ Impulse and Visionup Strobe Glasses that are also commercially available.

\section{Procedure}

All participants underwent pre-test and post-test phases 7 weeks apart, as well as a retention-test phase that occurred 4 weeks after the post-test. These involved the completion of a battery of seven tests of vision and perception (outlined in the "Measures" section below). The tests were undertaken individually in a quiet office at the academy training ground and took approximately $1 \mathrm{~h}$ in total to complete. On arrival to the pre-test, participants completed a general 
Fig. 1 a The Senaptec Strobe glasses with the lenses in the clear state. b The Senaptec Strobe glasses with the lenses in the opaque state
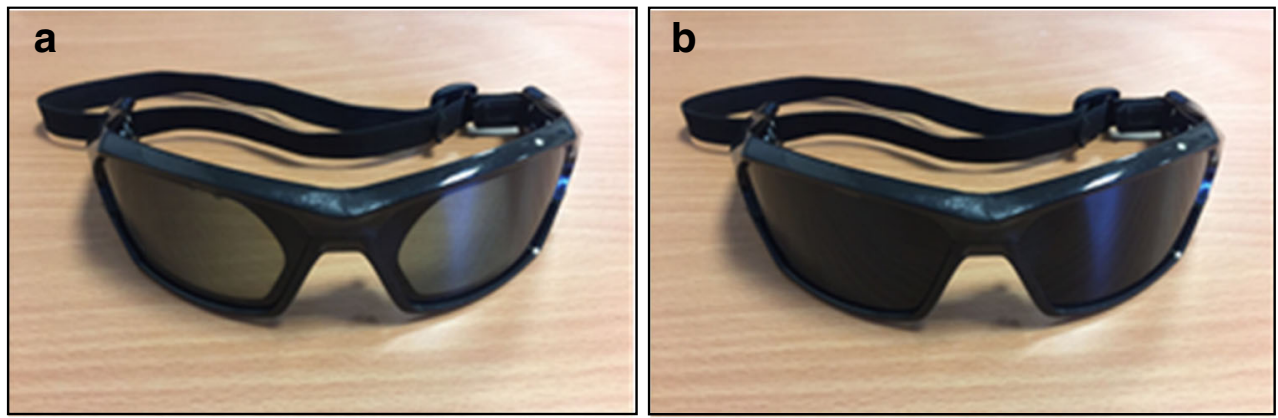

health questionnaire and signed a consent form to take part in the study. In between the pre- and post-test phases, the EG group took part in the SVT programme. All participants also continued their normal football training during this period, except for one player (hereafter referred to as EG2), who took part in a specialised rehabilitation programme for a knee injury (note: another player-hereafter referred to as EG3 - also missed 1 week of on-field training due to a minor knee injury). In both instances, the players were still able to perform a modified version of SVT that kept lower body movement to a minimum. No SVT was performed by any of the participants between the posttests and retention tests. Semi-structured, face-to-face interviews were conducted with each EG participant individually $10 \mathrm{~min}$ prior to the administration of the post-tests. Following the post-test, all participants were debriefed about the study and were provided with a report of the results. CG participants were also then offered the opportunity to undertake some SVT themselves.

\section{Measures}

The test battery consisted of seven tests (in order of completion): (1) the Team Sports Useful-Field-of-View (UFOV) test measuring processing speed, divided attention, and selective attention (Wilkins and Gray 2015); (2) the Reaction Test Pro app measuring visual response time; (3) the PEBL Compensatory Tracker test measuring handeye coordination; (4) the PEBL Go/No-Go test measuring response inhibition; (5) the PEBL Clock test measuring sustained attention; (6) the PEBL Timewall test measuring anticipation; and (7) the PEBL Corsi Block test measuring visual-spatial working memory. Screenshots of the Go/No-Go and Clock test are shown in Fig. 2.

Prior to each test, the experimenter explained what was required to each participant. For the UFOV, Clock, and Timewall tests, participants were given a short practice period of around 20-30 s to familiarise themselves further with the test requirements. A practice period was automatically built in to the Compensatory Tracker, Go/No-Go, and Corsi Block tests. For the Reaction Test Pro, participants completed 10 trials, with the first seven acting as practices, and the last three acting as test trials from which the final value was averaged.

The semi-structured interviews with each EG participant allowed for the collection of qualitative data regarding the nature of the SVT programme, thoughts on its effects (on both visual/perceptual performance and motor performance), preferred and less preferred aspects, and other related areas that the participant brought up themselves.

\section{Stroboscopic Training}

The EG group completed $10 \mathrm{~h}$ and $35 \mathrm{~min}$ of SVT over 7 weeks $(14 \times 45$-min sessions plus $1 \times 5$-min session immediately prior to the post-test). It has been suggested previously that discrepancies in visual training research may be due to the length of the visual training programme (Rezaee et al. 2012). The amount of training undertaken by the EG participants in the current study far exceeds the 4 weeks deemed insufficient by Rezaee et al. (2012) and is also considerably greater than other SVT studies which have produced significant findings (e.g. Appelbaum et al. 2011; Appelbaum et al. 2012; Holliday 2013; Mitroff et al. 2013; Smith and Mitroff 2012; Wilkins and Gray 2015).

All of the SVT took place in an indoor training facility at the academy training ground. Training sessions consisted of a combination of simple catching-based drills using a tennis ball (such as those in Wilkins and Gray 2015) and goalkeeperspecific drills using a football (as shown in Fig. 3). Sessions followed the same format as in previous SVT research in that participants practiced each drill for a short time without the glasses at first, then for a prolonged period with the glasses on, and then for a short time without the glasses to end. During the period in which the glasses were worn, participants made their way through eight levels of strobe difficulty and varied between the different eye modes, as described in the "Apparatus" section.

\section{Data Analysis}

Given the exploratory nature of the study, and the small sample size, no statistical tests were used to analyse the data. Pre- 
Fig. 2 a Image of the Clock test measuring sustained attention. $\mathbf{b}$ Image of the Go/No-Go test measuring inhibition response
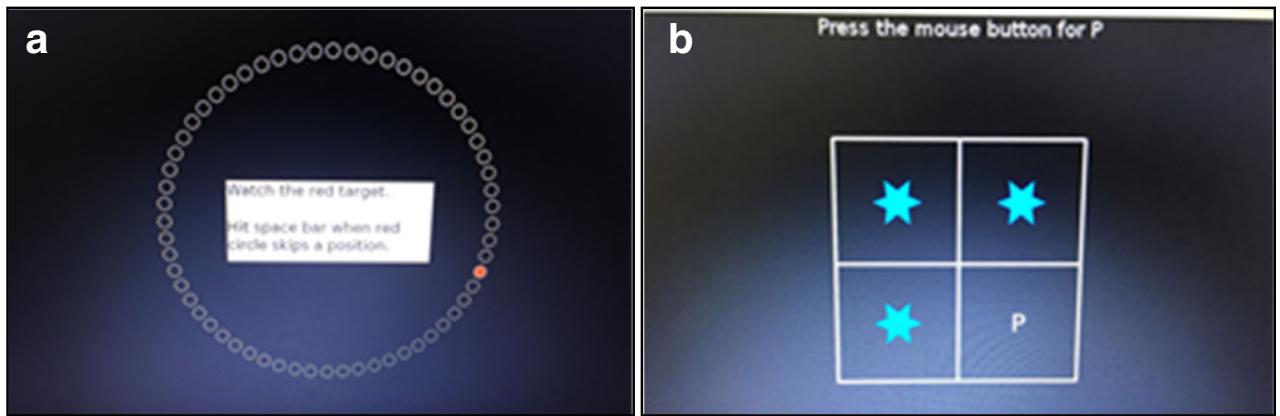

test, post-test, and retention test data were compared separately for each of the six participants.

The three sub-tests of the UFOV test produce scores in seconds, representing the length of time in which a stimulus appears that the participant achieves $75 \%$ correct performance on. As such, a lower value designates better performance. The Reaction Test Pro produces a value in seconds, with a lower value indicating better visual response time. The Compensatory Tracker test summates the total deviation from a central target, and therefore, a lower value equates to better hand-eye coordination. The Go/No-Go test produces two measures of response inhibition: accuracy (via total number of errors) and response speed (in seconds). In both cases, a lower value indicates better performance. The Clock test uses reaction time to determine sustained attention. Again, this is measured in milliseconds, and thus, a lower value represents better performance. The Timewall test produces a score in seconds that represents the error in anticipation time; therefore again, a lower score designates better performance. Finally, the Corsi Block test automatically computes an overall total score for visual-spatial working memory on completion. This is the only test in which a higher score is reflective of better performance.

A thematic analysis was conducted on the qualitative data taken from the semi-structured interviews. All interviews were transcribed from the initial voice recordings. They were then coded by hand to identify key words and concepts, after which the codings were analysed to categorise recurring themes. Specific quotations were highlighted within each finalised theme.

\section{Results}

\section{Quantitative Data}

The results of the visual and perceptual tests at pre-test, post-test, and retention test can be seen for the three EG participants in Table 1, and the three CG participants in Table 2. Figure $4 \mathrm{a}-$-jpresents the changes from pre-test to both post-test and retention test for each participant in each visual and perceptual test.

Participant EG1 showed consistent improvements (i.e. from both pre- to post-test and from pre-test to retention test) in 4 out of the 10 measures: selective attention, visual response time, hand-eye coordination, and inhibition response (reaction time). He showed consistent decreases in processing speed, sustained attention, and anticipation. Divided attention was poorer in the post-test but returned to pre-test levels in the retention test. Inhibition response (accuracy) and visual-spatial working memory declined from pre- to post-test but improved from pre-test to retention test.

Participant EG2 showed consistent improvements in 5 out of the 10 measures: divided attention, selective attention, visual response time, anticipation, and visual-spatial working memory. No notable changes were evident for inhibition
Fig. 3 a Image of an EG participant performing a goalkeeper-specific drill within the SVT programme. b Image of an EG participant performing a simple catching-based drill using a tennis ball within the SVT programme
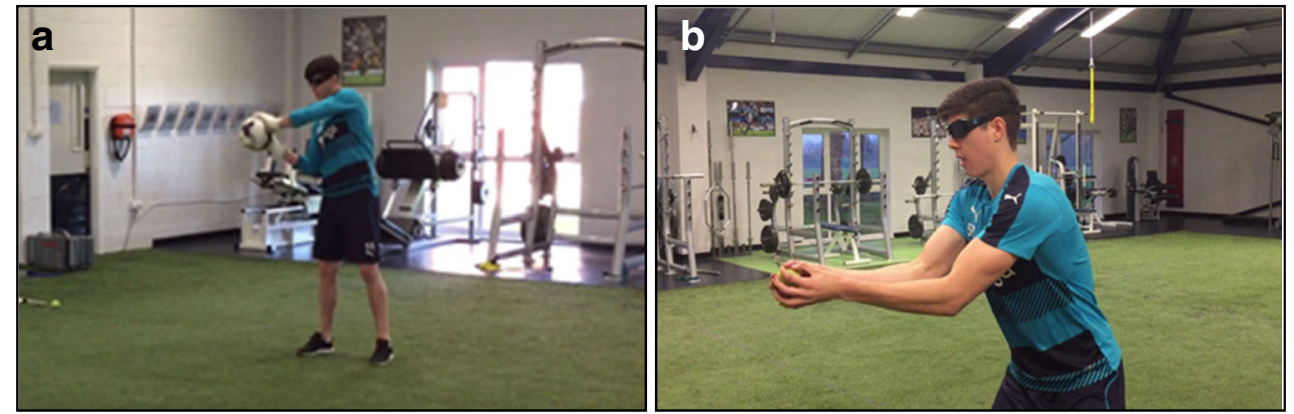
Table 1 Visual and perceptual performance of the three experimental group participants at pre-test (Pre), post-test (Post), and retention test (Ret)

\begin{tabular}{|c|c|c|c|c|c|c|c|c|c|c|}
\hline \multirow[t]{2}{*}{ Test } & \multirow[t]{2}{*}{ Measure } & \multicolumn{3}{|l|}{ EG1 } & \multicolumn{3}{|l|}{ EG 2} & \multicolumn{3}{|l|}{ EG 3} \\
\hline & & Pre & Post & Ret & Pre & Post & Ret & Pre & Post & Ret \\
\hline UFOV 1 & Processing speed & 0.032 & 0.077 & 0.061 & 0.010 & 0.017 & 0.012 & 0.142 & 0.025 & 0.023 \\
\hline UFOV 2 & Divided attention & 0.029 & 0.045 & 0.027 & 0.066 & 0.014 & 0.015 & 0.181 & 0.023 & 0.019 \\
\hline UFOV 3 & Selective attention & 0.207 & 0.169 & 0.097 & 0.111 & 0.097 & 0.034 & 0.240 & 0.232 & 0.225 \\
\hline Reaction Test Pro & Visual response time & 0.300 & 0.255 & 0.287 & 0.299 & 0.278 & 0.239 & 0.337 & 0.220 & 0.317 \\
\hline Compensatory Tracker & Hand-eye coordination & 19.575 & 17.942 & 14.276 & 14.541 & 15.486 & 12.183 & 17.647 & 14.965 & 11.462 \\
\hline Go/No-Go 1 & Response inhibition (accuracy) & 12 & 16 & 7 & 21 & 20 & 11 & 7 & 9 & 17 \\
\hline Go/No-Go 2 & Response inhibition (reaction time) & 0.470 & 0.440 & 0.440 & 0.421 & 0.426 & 0.419 & 0.433 & 0.423 & 0.416 \\
\hline Clock & Sustained attention & 0.327 & 0.308 & 0.364 & 0.386 & 0.379 & 0.380 & 0.371 & 0.345 & 0.343 \\
\hline Timewall & Anticipation & 0.033 & 0.040 & 0.039 & 0.031 & 0.023 & 0.027 & 0.057 & 0.032 & 0.060 \\
\hline Corsi Block & Visual-spatial working memory & 96 & 60 & 117 & 80 & 104 & 88 & 40 & 54 & 40 \\
\hline
\end{tabular}

Lower scores indicate better performance in all tests except Corsi Block, in which a higher score indicates better performance

response (reaction time) or sustained attention in both the post-test and retention test. Processing speed was worse in the post-test but had returned to pre-test levels in the retention test. Hand-eye coordination was also poorer in the post-test, before then improving beyond pre-test levels in the retention test, whilst inhibition response (accuracy) declined in the posttest before again improving beyond pre-test levels in the retention test.

Participant EG3 showed consistent improvements in 7 out of the 10 measures: processing speed, divided attention, selective attention, visual response time, handeye coordination, inhibition response (reaction time), and sustained attention. He performed consistently worse in only one measure: inhibition response (accuracy). Anticipation improved from pre- to post-test but declined from pre-test to retention test. Visual-spatial working memory improved in the post-test but returned to pretest levels in the retention test.

Participant CG1 showed consistent improvements in 5 out of the 10 measures: processing speed, divided attention, selective attention, sustained attention, and anticipation. $\mathrm{He}$ performed consistently worse in visual response time. Hand-eye coordination was worse in the post-test and better in the retention test, whilst visual-spatial working memory was better in the post-test before returning to pre-test levels in the retention test. Inhibition response scores did not change in the post-test, yet in the retention test the accuracy measure declined and the reaction test measure improved compared to pre-test levels.

Participant CG2 showed consistent improvements in 6 out of the 10 measures: divided attention, selective attention, hand-eye coordination, inhibition response (accuracy and

Table 2 Visual and perceptual performance of the three control group participants at pre-test (Pre), post-test (Post), and retention test (Ret)

\begin{tabular}{|c|c|c|c|c|c|c|c|c|c|c|}
\hline \multirow[t]{2}{*}{ Test } & \multirow[t]{2}{*}{ Measure } & \multicolumn{3}{|l|}{ CG1 } & \multicolumn{3}{|l|}{$\mathrm{CG} 2$} & \multicolumn{3}{|l|}{ CG3 } \\
\hline & & Pre & Post & Ret & Pre & Post & Ret & Pre & Post & Ret \\
\hline UFOV 1 & Processing speed & 0.067 & 0.054 & 0.014 & 0.019 & 0.017 & 0.021 & 0.027 & 0.017 & 0.167 \\
\hline UFOV 2 & Divided attention & 0.219 & 0.134 & 0.207 & 0.032 & 0.020 & 0.021 & 0.208 & 0.088 & 0.079 \\
\hline UFOV 3 & Selective attention & 0.269 & 0.227 & 0.229 & 0.224 & 0.151 & 0.166 & 0.245 & 0.227 & 0.216 \\
\hline Reaction Test Pro & Visual response time & 0.261 & 0.321 & 0.310 & 0.239 & 0.179 & 0.255 & 0.262 & 0.265 & 0.267 \\
\hline Compensatory Tracker & Hand-eye coordination & 17.242 & 17.453 & 12.266 & 15.144 & 14.848 & 9.827 & 19.498 & 16.957 & 14.372 \\
\hline Go/No-Go 1 & Response inhibition (accuracy) & 10 & 9 & 23 & 14 & 10 & 11 & 5 & 2 & 7 \\
\hline Go/No-Go 2 & Response inhibition (reaction time) & 0.485 & 0.482 & 0.447 & 0.411 & 0.392 & 0.391 & 0.455 & 0.472 & 0.464 \\
\hline Clock & Sustained attention & 0.455 & 0.378 & 0.424 & 0.317 & 0.323 & 0.323 & 0.388 & 0.362 & 0.420 \\
\hline Timewall & Anticipation & 0.052 & 0.035 & 0.043 & 0.040 & 0.039 & 0.038 & 0.026 & 0.031 & 0.045 \\
\hline Corsi Block & Visual-spatial working memory & 54 & 96 & 54 & 88 & 72 & 40 & 99 & 88 & 80 \\
\hline
\end{tabular}

Lower scores indicate better performance in all tests except Corsi Block, in which a higher score indicates better performance 

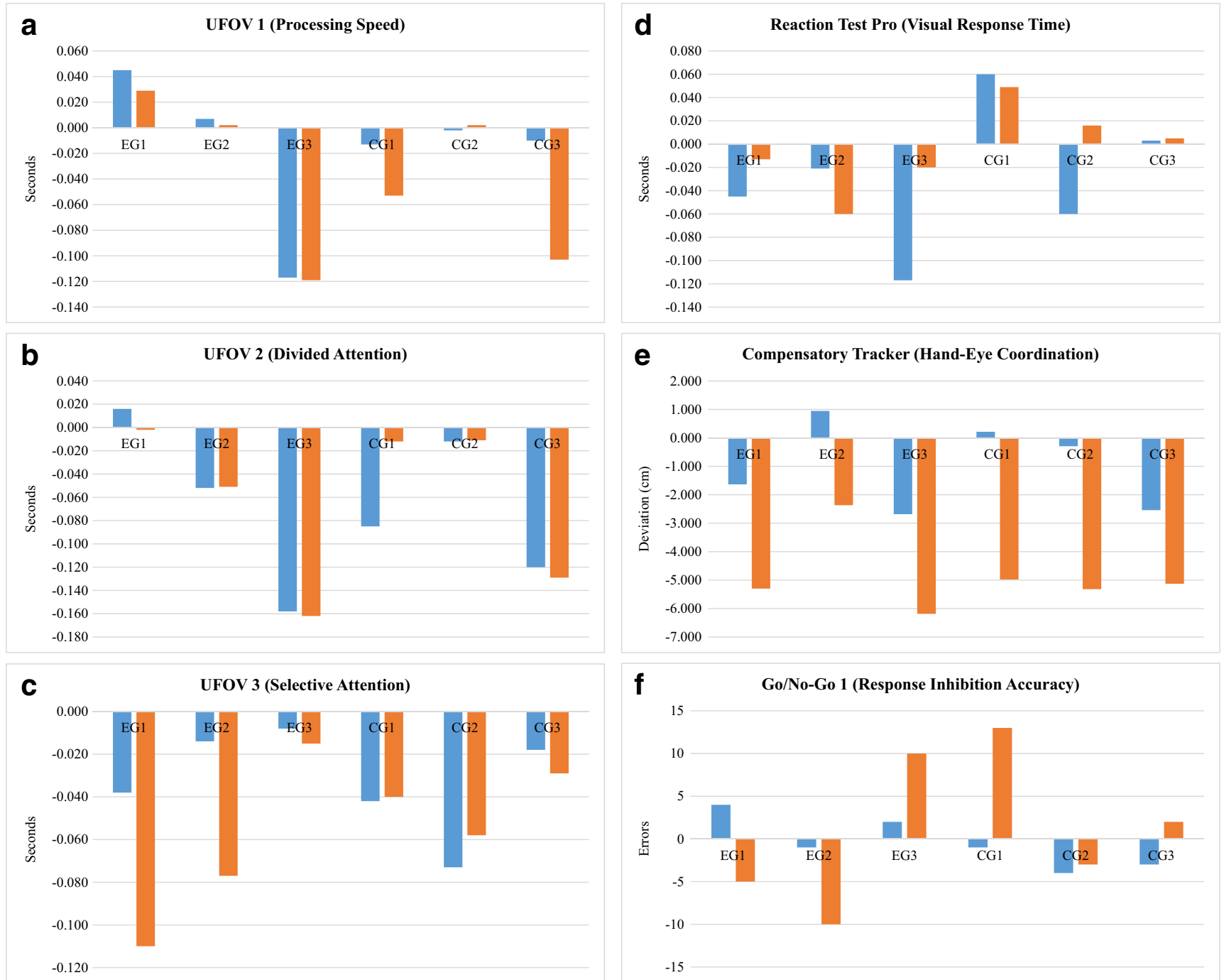

Fig. 4 a Change in UFOV 1 (processing speed) scores from pre-test to post-test (blue) and retention test (orange) for each participant. b Change in UFOV 2 (divided attention) scores from pre-test to post-test (blue) and retention test (orange) for each participant. c Change in UFOV 3 (selective attention) scores from pre-test to post-test (blue) and retention test (orange) for each participant. d Change in Reaction Test Pro (visual response time) scores from pre-test to post-test (blue) and retention test (orange) for each participant. e Change in Compensatory Tracker (handeye coordination) scores from pre-test to post-test (blue) and retention test (orange) for each participant. f Change in Go/No-Go 1 (response

reaction time), and visual-spatial working memory. A consistent decline was found in sustained attention, whilst neither processing speed nor anticipation changed from pre-test to post-test/retention test. Visual response time improved in the post-test but declined from pre-test levels in the retention test.

Participant CG3 showed consistent improvements in 3 out of the 10 measures: divided attention, selective attention, and hand-eye coordination. He also performed consistently worse in three measures: inhibition response (reaction time), anticipation, and visual-spatial working memory. Processing speed, inhibition response (accuracy),

inhibition accuracy) scores from pre-test to post-test (blue) and retention test (orange) for each participant. g Change in Go/No-Go 2 (response inhibition reaction time) scores from pre-test to post-test (blue) and retention test (orange) for each participant. h Change in Clock (sustained attention) scores from pre-test to post-test (blue) and retention test (orange) for each participant. i Change in Timewall (anticipation) scores from pre-test to post-test (blue) and retention test (orange) for each participant. j Change in Corsi Block (visual-spatial working memory) scores from pre-test to post-test (blue) and retention test (orange) for each participant

and sustained attention were all better in the post-test, before decreasing below pre-test levels in the retention test. Visual response time did not change from pre-test to either post-test or retention test.

\section{Qualitative Data}

The thematic analysis of the semi-structured interview data identified three consistent themes. These were as follows: (1) a belief that the SVT improved visual and perceptual skills, notably "focus", "reactions", and "judgement"; (2) a belief that the 

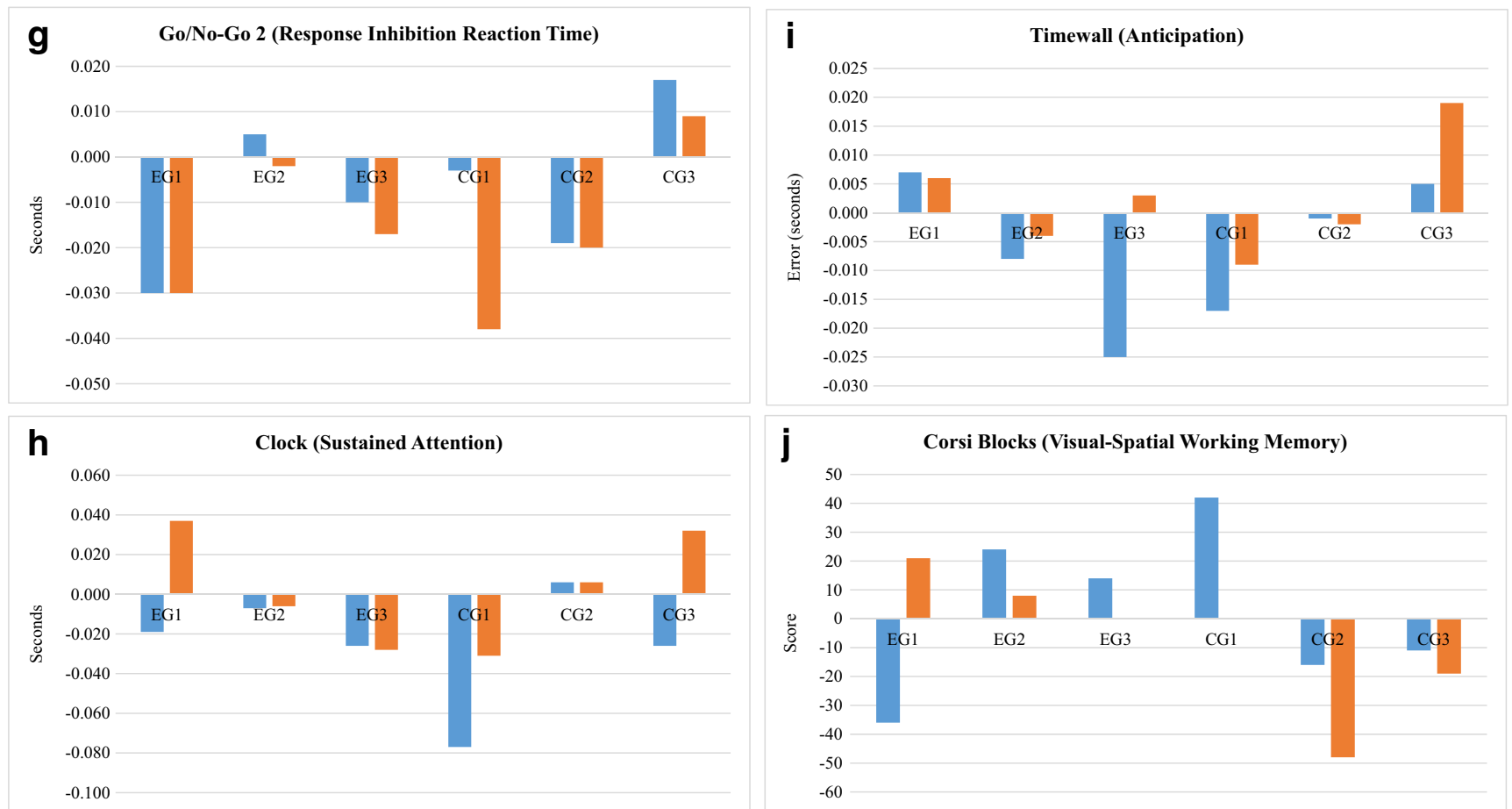

Fig. 4 continued.

SVT improved on-field goalkeeping performance; and (3) that the SVT was both effortful and enjoyable. Specific quotes relating to these themes can be seen in Table 3 .

\section{Discussion}

The present pilot study aimed to expand on research in the growing field of stroboscopic visual training. To do so, six elite youth football goalkeepers took part, with three undergoing a 7-week SVT programme, and three acting as a control. The quantitative data collected showed that generally both EG and CG participants improved to similar degrees in 9 out of the 10 measures of visual and perceptual skills. The one measure that did show some promise for advocating the benefits of SVT was visual response time, which saw improvements from pre- to post-test and pre-test to retention test for all three EG
Table 3 Selected quotes from the semi-structured interview data

\begin{tabular}{|c|c|c|}
\hline Theme & Quote & Participant \\
\hline $\begin{array}{l}\text { Improved visual and } \\
\text { perceptual skills } \\
\text { (judgement) }\end{array}$ & $\begin{array}{l}\text { "...then you take the glasses off everything's way easier to like, to } \\
\text { read the ball, and just, judge the flight of it and the angle of } \\
\text { where to get your hands and stuff...Just the whole judgement } \\
\text { kind of thing will probably improve quite a lot" }\end{array}$ & EG2 \\
\hline $\begin{array}{l}\text { Improved visual and } \\
\text { perceptual skills } \\
\text { (reactions) }\end{array}$ & $\begin{array}{l}\text { "My reactions have probably got a lot better as well...Your } \\
\text { reactions are just so much sharper" }\end{array}$ & EG2 \\
\hline $\begin{array}{l}\text { Improved visual and } \\
\text { perceptual skills (focus) }\end{array}$ & $\begin{array}{l}\text { "...you've got such a focus on the ball, it seems so much easier to } \\
\text { catch than what it would normally" }\end{array}$ & EG3 \\
\hline $\begin{array}{l}\text { Improved on-field } \\
\text { goalkeeping performance }\end{array}$ & "I think I have felt a benefit when I go out for training" & EG1 \\
\hline $\begin{array}{l}\text { Improved on-field } \\
\text { goalkeeping performance }\end{array}$ & $\begin{array}{l}\text { "...I could feel the difference when I went out to train like straight } \\
\text { after, that it was just, like it felt so much easier...You just seem } \\
\text { to move your feet quicker" }\end{array}$ & EG3 \\
\hline Effortful and enjoyable & $\begin{array}{l}\text { "I remember the first few sessions I used to come out, like } \\
\text { absolutely exhausted - sweating from concentration...(I) } \\
\text { Loved it" }\end{array}$ & EG2 \\
\hline Effortful and enjoyable & $\begin{array}{l}\text { "I'd like to do it every day if I could...It was hard, but it was } \\
\text { enjoyable" }\end{array}$ & EG3 \\
\hline
\end{tabular}


participants, but an improvement from pre- to post-test for one only CG participant, and no improvement for any CG participants from pre-test to retention test.

Interestingly, this is in line with the qualitative data in which one of the three themes that emerged was the belief that SVT improved visual and perceptual skills, notably "reactions". This term — used by the EG participants—is likely interchangeable with visual response time from the goalkeepers' perspectives. Improved "judgement" and "focus" were other specific skills highlighted, whilst improved on-field goalkeeping performance and the belief that SVT was effortful and enjoyable were the two other themes identified from the thematic analysis. Such findings are in line with the vast anecdotal evidence, which advocates the use of SVT from a sports performance perspective (Athletic Republic 2011).

However, the quantitative results are in contrast to much of the existing literature on SVT that tends to find that participants improve on a range of visual and perceptual skills. Indeed, anticipation (Smith and Mitroff 2012), divided attention (Appelbaum et al. 2011), and hand-eye coordination (Jones et al. 2016) were all measures that have been found to benefit from SVT, yet showed no improvement (greater than the CG) in the present study. In each case, however, the actual test used to measure these skills differed to that of the present study. It is possible that these alterations, along with differences in sporting ability (most previous work has used novice or intermediate athletes), may explain the conflicting results. It should be noted, though, that Appelbaum et al. (2011) failed to find any effect of SVT on sustained attention (again using a different task) which is in concordance with the findings of this study.

Despite the practice afforded to participants prior to the visual and perceptual tests, it is likely that the results were impacted by practice/familiarity effects. This would explain the improvements that occurred for the control group, despite undergoing no SVT training. This is something that future research should be aware of. Whilst it is not believed that boredom was a factor in either the testing or training phases, it is possible that the lengths employed were on the borderline (the test phases lasted approximately $1 \mathrm{~h}$ and the training sessions were $45 \mathrm{~min}$ ). It is recommended that future work does not exceed these times.

Future studies should look to build on the results found here by including larger samples that allow for statistical analyses. In particular, exploring measures of judgement and focus may be useful, given the qualitative findings. Work should also aim to include a measure of sporting/ motor performance, especially if elite athletes are being used. Whilst this can be difficult to control adequately, particularly for positions such as the goalkeeper, it is essential in order to determine the practical implications of SVT. Finally, given that EG2 was injured throughout the duration of the study and therefore did not take part in any normal football training, it would be interesting to see whether SVT can be used as a way of maintaining (or even improving) the visual and perceptual skills that may deteriorate through underuse in injured athletes.

If SVT can indeed improve the visual response time of athletes, then this has huge implications for a variety of sports. Response times have been shown to differentiate skill levels in sports such as basketball (Ghuntla et al. 2012), sprinting (Tønnessen et al. 2013), table tennis (Hughes et al. 1993), handball (Zwierko 2007), water-polo (Kioumourtzoglou et al. 1998), and rugby (Gabbett and Abernethy 2013), and therefore, the implementation of SVT into training routines may be key for the development of athletes. SVT is a relatively simple tool that maintains real-world context, can be conducted indoors, and, as seen with the present study, can be done with injured athletes. The qualitative findings suggest that football goalkeepers would benefit from introducing SVT from both the direct impact on onfield performance and the indirect impact of enhanced enjoyment. Extensive research has shown enjoyment to be linked to both motivation (McCarthy and Jones 2007) and sporting performance (Cerasoli et al. 2014), and therefore, at the very least, SVT may have a positive placebo effect on athletes.

The current work is, to the authors' knowledge, the first SVT study to utilise a qualitative approach to examine participants' thoughts and feelings towards SVT and to empirically examine the abundance of anecdotal evidence that there is on the topic. The study also used a novel participant group and incorporated a vast array of visual and perceptual measures, including ones that have yet to be investigated with regards to SVT such as inhibition response and visual-spatial working memory (other aspects of visual memory have been investigated). The SVT programme undertaken by the goalkeepers was also the longest, in terms of hours, ever conducted amongst the published research, satisfying Rezaee et al.'s (2012) assertion that visual training research is often too short. Finally, the 4-week retention test allowed for the long-term effects of SVT to be investigated, a factor that has often been overlooked in previous work.

The present pilot study suggests that SVT may have the potential to improve the visual response time of elite youth athletes. Evidence for the benefits of SVT on a wide range of other visual and perceptual skills, including attention, anticipation, and hand-eye coordination, was not found. Despite this, qualitative data from interviews provided strong support for the anecdotal evidence of SVT benefits. Further research is needed which expands on this work and incorporates sporting/ motor performance measures.

Acknowledgements Thanks must be given to all the staff at Newcastle United Football Club Academy, in particular, academy goalkeeping coach Chris Terpcou and the six goalkeepers who took part in the project.

Compliance with Ethical Standards The study was approved by the Faculty of Medical Sciences Research Ethics Committee, part of Newcastle University's Research Ethics Committee. 
Open Access This article is distributed under the terms of the Creative Commons Attribution 4.0 International License (http:// creativecommons.org/licenses/by/4.0/), which permits unrestricted use, distribution, and reproduction in any medium, provided you give appropriate credit to the original author(s) and the source, provide a link to the Creative Commons license, and indicate if changes were made.

\section{References}

Abernethy, B., \& Wood, J. M. (2001). Do generalized visual training programmes for sport really work? An experimental investigation. Journal of Sports Sciences, 19(3), 203-222.

Appelbaum, L.G., \& Erickson, G. (2016). Sports vision training: a review of the state-of-the-art in digital training techniques. International Review of Sport and Exercise Psychology, 1-30. https://doi.org/10. 1080/1750984X.2016.1266376.

Appelbaum, L. G., Schroeder, J. E., Cain, M. S., \& Mitroff, S. R. (2011). Improved visual cognition through stroboscopic training. Frontiers in Psychology, 2, 276.

Appelbaum, L. G., Cain, M. S., Schroeder, J. E., Darling, E. F., \& Mitroff, S. R. (2012). Stroboscopic visual training improves information encoding in short-term memory. Attention, Perception, \& Psychophysics, 74(8), 1681-1691.

Appelbaum, L. G., Lu, Y., Khanna, R., \& Detwiler, K. R. (2016). The effects of sports vision training on sensorimotor abilities in collegiate softball athletes. Athletic Training \& Sports Health Care, 8(4), 154-163.

Athletic Republic (2011) NFL players see sport better with the Nike SPARQ Vapor Strobe [video file]. Retrieved from https://www. youtube.com/watch?v=A3Wir88Zvh8. Accessed 7 Dec 2016.

Cerasoli, C. P., Nicklin, J. M., \& Ford, M. T. (2014). Intrinsic motivation and extrinsic incentives jointly predict performance: A 40-year meta-analysis. Psychological Bulletin, 140(4), 980-1008.

Clarke, J. F., Ellis, J. K., Bench, J., Khoury, J., \& Graman, P. (2012). High-performance vision training improves batting statistics for university of Cincinnati baseball players. PloS One, 7(1), e29109.

Clarke, J. F., Colosimo, A., Ellis, J. K., Mangine, R., Bixenmann, B., Hasselfeld, K., Graman, P., Elgendy, H., Myer, G., \& Divine, J. (2015). Vision training methods for sports concussion mitigation and management. Journal of Visualized Experiments, 99, e52648.

Gabbett, T. J., \& Abernethy, B. (2013). Expert-novice differences in the anticipatory skill of rugby league players. Sport, Exercise, and Performance Psychology, 2(2), 138-155.
Ghuntla, T. P., Mehta, H. B., Gokhale, P. A., \& Shah, C. J. (2012). A comparative study of visual reaction time in basketball players and healthy controls. National Journal of Integrated Research in Medicine, 3(1), 49-51.

Holliday $\mathbf{J}$ (2013) Effect of stroboscopic vision training on dynamic visual acuity scores: Nike Vapor Strobe eyewear. All Graduate Plan B and other Reports, paper 262.

Hughes, P. K., Bhundell, N. L., \& Waken, J. M. (1993). Visual and psychomotor performance of elite, intermediate and novice table tennis competitors. Clinical and Experimental Optometry, 76(2), $51-60$.

Jones, C., Carnegie, E., \& Ellison, P. (2016). The effect of stroboscopic vision training on eye-hand coordination. Cardiff: Paper presented at the British Psychological Society Division of Sport \& Exercise Psychology Conference.

Kioumourtzoglou, E., Kourtessis, T., Michalopoulou, M., \& Derri, V. (1998). Differences in several perceptual abilities between experts and novices in basketball, volleyball and water-polo. Perceptual and Motor Skills, 86, 899-912.

McCarthy, P. J., \& Jones, M. V. (2007). A qualitative study of sport enjoyment in the sampling years. The Sport Psychologist, 21, 400-416.

Mitroff, S. R., Friesen, P., Bennett, D., Yoo, H., \& Reichow, A. W. (2013). Enhancing ice hockey skills through stroboscopic visual training: a pilot study. Athletic Training \& Sports Health Care, 5, 1-5.

Mueller, S. T., \& Piper, B. J. (2014). The psychology experiment building language (PEBL) and PEBL test battery. Journal of Neuroscience Methods, 222, 250-259.

Rezaee, M., Ghasemi, A., \& Momeni, M. (2012). Visual and athletic skills training enhance sport performance. European Journal of Experimental Biology, 2(6), 2243-2250.

Smith, T. Q., \& Mitroff, S. R. (2012). Stroboscopic training enhances anticipatory timing. International Journal of Exercise Sciences, 5(4), 344-353.

Tønnessen, E., Haugen, T., \& Shalfawi, S. A. I. (2013). Reaction time aspects of elite sprinters in athletic world championships. Journal of Strength and Conditioning Research, 27(4), 885-892.

Wilkins, L., \& Gray, R. (2015). Effects of stroboscopic visual training on visual attention, motion perception, and catching performance. Perceptual and Motor Skills, 121, 57-79.

Williams, A. M., Ford, P. R., Eccles, D. W., \& Ward, P. (2011). Perceptual-cognitive expertise in sport and its acquisition: Implications for applied cognitive psychology. Applied Cognitive Psychology, 25, 432-442.

Zwierko, T. (2007). Differences in peripheral perception between athletes and nonathletes. Journal of Human Kinetics, 19, 53-62. 